\title{
TEXTOS LINGÜÍSTICOS ANTIGUOS DEL ROMANCE HISPÁNICO
}

\author{
Micaela CarRera de la Red \\ Universidad de Valladolid
}

INTRODUCCIÓN: GLOSAS Y GLOSARIOS

El conocimiento del romance hispánico de orígenes, así como de la lengua romance de los textos literarios primitivos, ha avanzado mucho en nuestro tiempo. El estudio de algunas fuentes medievales, tales como los diplomas latinos con términos y expresiones en lengua vulgar, los códices glosados y los glosarios latinos, romances y mozárabes, son uno de los caminos más fructíferos que pueden seguirse para adentrarse en el análisis de la fase de continuum lingüístico que debe suponerse en el centro peninsular durante los siglos VIII, IX, X y XI.

Es, sobre todo, en este último siglo o incluso en el anterior, donde se halla toda una serie de intentos deliberados de volver al romance escrito el latín que era la lengua de prestigio.

En esa dirección caminaban los glosadores hispanos, cuyo trabajo intentamos situar y valorar debidamente.

La voz glosa es un calco del griego $\gamma \lambda \tilde{\omega} \sigma \sigma \alpha$ 'órgano llamado lengua' y 'lenguaje'. En el siglo IV el poeta latino-cristiano Ausonio la emplea en el sentido de «palabra rara, desconocida, a la que se añade una explicación». A esos términos o expresiones aclaratorias es a lo que ahora llamamos glosas. 
Se dice que este empeño por aclarar el lenguaje empezó en Roma durante la época de Augusto por obra de algunos lexicógrafos, el más conocido de los cuales es Marco Verrio Flaco con su tratado De verborum significatione (Sobre el significado de las palabras). Esta obra fue extractada para las escuelas en el siglo II por Sexto Pompeyo Festo, gramático, que a su vez fue resumido en el s. VIII por Paulo Diácono, escritor longobardo, que en la corte de Carlomagno fue uno de los más notables impulsores del Renacimiento Carolingio.

La obra más glosada era naturalmente la Biblia, y las aclaraciones que se le añadieron formaron, compiladas, la llamada Glosa Antigua, que fue muy mejorada en el siglo IX por Walafrido Estrabón (\$849), discípulo de Rabano Mauro.

Pero no sólo se glosaba la Biblia, sino también a los autores clásicos como Cicerón, Virgilio y Terencio. Y no sólo eran los monjes los que añadían glosas, sino otros gramáticos, como Servio Honorato (fines del siglo IV), que glosó a Virgilio, y Fabio Planciades Fulgencio, autor cristiano africano de fines del siglo $\mathrm{V}$, que hizo lo mismo.

Las glosas que se habían hecho a esto autores clásicos y a la Biblia fueron compiladas más tarde, en el siglo VII, en un corpus que se conoce como Glossae collectae (Compilación de glosas), sacadas de Virgilio, Terencio, Lucano y otros. ${ }^{1}$

A la labor de los glosistas, como a las demás ramas del saber, contribuyó enormemente San Isidoro de Sevilla (+636), cuyas obras, sobre todo la de las Etimologías, fueron la más copiosa fuente de términos de que se nutren los glosarios latinos posteriores.

Él mismo, al escribir sus tratados, va introduciendo en el texto numerosas aclaraciones sobre las palabras que sospecha pueden encerrar dificultades para que las comprendan sus lectores. Son verdaderas glosas añadidas por él a su propio lenguaje. Algunos ejemplos:

- Framea, 'que vulgarmente se llama espada' (Etim XVIII,6.24)

- Palumbes, 'a las que la gente llama torcaces' (Etim XII,7.62)

- Epilemsia, 'enfermedad que a los que la padecen, la gente los llama lunáticos' (Etim IV, 7.5)

- Camisias, 'así llamadas porque con ellas nos vamos a la cama' (Etim XIX, 22.20)

- Phaselus, 'una nave que llamamos bajel, por corrupción del nombre' (Etim XIX,1.17)

1 Ver J.D. Pheifer, «How not to edit Glossariesm, en Scragg \& Szarmach (eds.), The Editing of Old English, Cambridge, 1994, 269-280. 
Los métodos de enseñanza que se llevaban en las escuelas de Europa exigían para la utilidad de los escolares disponer de unas listas de voces latinas que cada vez se entendían con mayor dificultad y que convenía explicar por otros términos más comprensibles. A tales vocabularios se les da el nombre de Glosarios.

A los pocos años de morir San Isidoro, los monjes de Sant Gall (Suiza) compusieron un glosario latino, que es el más antiguo de los que se conservan. Es de fines del siglo VII, y se le conoce como «Sant Gallen, $n .{ }^{\circ} 912 » .{ }^{2}$

Del mismo tiempo es el Glosario de Épinal, que se guarda en la Biblioteca de esa ciudad francesa. Aunque es un glosario latín-latín, en una tercera o cuarta parte de sus voces es latín explicado en glosas del inglés antiguo. ${ }^{3}$

Apuntó Menéndez Pidal las coincidencias de algunas de las glosas hispanas con las llamadas Glossae Abavus del siglo IX, y con las Glosas de Reichenau. Éstas toman el nombre de la antigua abadía de Reichenau en una pequeña isla del lago de Constanza. Son glosas latino-romances, en parte, y se dice que fueron escritas en el siglo VIII en el norte de la Galia. Por esa razón las mencionamos a ambas especialmente. ${ }^{4}$

A más de los citados, en toda la Europa donde dominó el latín medieval, se escribieron gran número de Glosarios, ś́lo latinos o latinos y con glosas en lengua vemácula de cada país, que desde el siglo XIX hasta hoy se han recogido en voluminosas colecciones. La más difundida es el Corpus Glossarium Latinorum (Cuerpo de Gosarios Latinos-CGL), editado por G. Goetz (7 vols., Leipzig, 1888-1923). ${ }^{5}$

\section{LAS GLOSAS EN ESPAÑA}

Las glosas en la Edad Media se escribieron con una intención pedagógica: para enseñar a los escolares el latín, o para hacer comprensibles a los mayores algunos textos latinos. En ambos supuestos el objetivo era siempre llegar a un mejor conocimiento del latín.

2 Sant Gallen, Stiftsbibliothek, cod. 912, impreso en el Corpus Glossariorum Latinorum, V.337-401.

${ }^{3}$ Epinal, capital del dep. de los Vosgos, junto al Mussela, Cod. Épinal, Bibliothèque Municipale, 72(2), impreso en E.A. LowE (ed.), Codices Latini Antiquiores, Oxford, 1934-71 (11 vols.), VI, n. ${ }^{\circ} 760$.

4 Glossarium Abavus (Leiden 67F, fol.62r-104r), en CGL IV,301-403. Glosas de Reichenau, en CGL VIII,156a.

5 Otras colecciones: W.M. Lindsay (ed.),Glossaria Latina (GL), Paris, 1926-1931 (5 vols.).Gustav Lowe (ed.), Prodromus Corporis Glossariorum Latinorum (el precursor de los GL), Leipzig, 1876.- Gustav Lowe (ed.),Glossae Nominum, Leipzig. 1884. 
En la actualidad, en cambio, las glosas son estudiadas para conocer mejor las lenguas vernáculas, sean célticas, germánicas o romances. Porque los glosistas escribieron en un contexto en que sus lenguas matemas estaban en ebullición, tratando de hacerse capaces de expresar en los libros cualquier pensamiento, como lo hacían aquellos que escribían en latín. Y tuvieron que dar los primeros pasos, aunque fueran rudimentarios, y ello tiene gran interés para los lexicógrafos. Y de ahí que para nosotros tenga su importancia el estudio de las glosas hispánicas.

No obstante, de entrada pudiera alguien hacerse dos preguntas: $i$ se escribieron muchas glosas en España? ¿Y las que se escribieron eran latinas o romances?

Una sucinta reseña de códices españoles con glosas y de los glosarios puede dar una panorámica de la actividad glosística de nuestros monasterios. ${ }^{6}$

\section{CÓDICES CON GLOSAS}

Hay dos códices que son fundamentales por el número y la calidad de glosas romances que contienen, y son el Códice de las Glosas Emilianenses y el Códice de las Glosas Silenses. De ellos nos ocuparemos más adelante.

Otros códices que ofrecen repertorios de glosas son los siguientes:

1. Real Academia de la Historia (RAH), $m s .13$, del $2 .^{\circ}$ tercio del siglo X, escrito en San Millán de la Cogolla. Vidas de santos, con muchas glosas latinas, que ya estaban en el modelo que copiaba. ${ }^{?}$

2. Fragmentos Najerenses 5.16 , de la $2^{\mathrm{B}}$ mitad del siglo $\mathrm{X}$, se conservan en Silos. Contienen parte de los Comentarios de Esmaragdo a la Regla de San Benito. Tiene glosas latinas que en toda Europa solían llevar dichos Comentarios. ${ }^{8}$

3. Códice Vigilano del Escorial, ms.d.1.2, del año 992. En los folios 359-360 contiene un Penitencial (lista de pecados y la penitencia que les corresponde) con muchas glosas latinas, y tiene gran interés

- Para una relación detallada de glosarios y manuscritos con glosas, ver M.C.Diaz y DiAZ, Las primeras glosas hispánicas, Barcelona, Univ. Autónoma, 1978. Este autor ha prestado gran atención a las glosas en otras publicaciones, entre las que destaca: Libros y librerías de la Rioja altomedieval, Logroño, Instituto de Estudios Riojanos, 1979, y «Las glosas protohispánicas», en Actas del III Congreso Internacional de Historia de la Lengua Española, AlvARo González y otros (eds.), Madrid, Arco Libros, t.I, 1996,653-666.

' M.C.DIAZ Y DIAZ, Libros y librerias, 1979, 133-140.

${ }^{8}$ M.C.DIAZ y DIAZ, Libros y librerías, 1979, 44-45. 
porque varias de ellas coinciden con las latinas que se hallan en las Glosas Silenses. ${ }^{9}$

4. British Library, add. 25600 , del s.X, copiado en San Pedro de Cardeña (Burgos). Es un libro litúrgico con abundantes glosas latinas que recuerdan a las Glosas Emilianenses. ${ }^{10}$

5. British Library, add. 30851, del siglo XI, escrito en Silos. Es un salterio con un Liber hymnorum (conjunto de himnos litúrgicos). Tiene 585 glosas de las cuales unas 30 son términos romances. "

\section{GLOSARIOS}

Dos centros culturales de primer orden como San Millán y Silos, dotados de grandes escriptorios y excelentes bibliotecas, no podían menos de tener también los imprescindibles diccionarios de glosas. Se han conservado tres de cada uno de estos monasterios.

1) $R A H$, cód.24, año 917, San Millán. Entre los folios 150-154 copia un glosario latino incompleto, desde la letra $\mathrm{D}$ a los principios de la P. ${ }^{12}$

2) $R A H$,cód.46, año 964, San Millán. Glosario latino con algunas glosas en lengua germánica; va del fol.1 al 168. En San Millán se le conocía como Glossarium Abauus por su similitud con las Glossae Abauus que corrían por Europa. ${ }^{13}$

3) $R A H$,cód.31, siglo XI, de San Millán, tal vez procedente del monasterio de San Juan de la Peña (Huesca). También glosario incompleto desde los finales de la A hasta los de la S. Sigue al Liber Glossarum atribuido al visigodo Ansileubus, escrito en el siglo IX ó X. ${ }^{14}$

${ }^{9}$ M.C.DiAZ y DiAZ, Las glosas protohispánicas, 1996, 658. En la nota ofrece algunas glosas de este códjce que son idénticas y otras que se aproximan mucho a las del Penitencial Silense,vg. abluat :

abluat: mundat, labat

uiolaberit: rapuerint

more: usuale

preuigna: ante nata

gestiunt: capiunt, etc.

in R. WRIGHT, Latín tardio y romance temprano, Madrid, Gredos, 1989. 296-298.

1 M.C.DIAZ Y DfAZ, Las glosas protohispánicas.

12 Libros y librerías, 1979, 222-223.

${ }^{13}$ Libros y librerías, 1979, 143-147. Apéndice XX: Relación de códices emilianenses en 1821. $n^{\circ} 31$ : Otro en $4^{\circ}$ mayor de letra del siglo XI, y es vocabulario de idioma latino, y á la letra $S$ le falta un cuaderno de 8 hojas. = Madrid BAH, cód. 46 [F.212]: Glossarium Abauus. [EWALD-Loewe, 19; Loewe-Hartel, 513,n. 44; Clark, 40; Garcia Villada, n. 97; Millares, PE, 463 n. 159; KLEIN, 558, 561; DiAZ, Glosas 13, v. p. 143-147.

${ }^{14}$ Libros y librerias, 1979:186-187. 
También los monjes de Silos copiaron tres amplios glosarios latinos que, por desgracia para nosotros, salieron de su biblioteca par ir a parar a la Biblioteca Nacional de París, nouvelles acquisitiones latines 1296 (siglos X-XI) y 1297 (siglo XII), publicados en 1933 por García de Diego, y el 1298 (sigloXI), publicado por García de Diego y por Goetz en 1894. ${ }^{15}$ Los códices 1296 y 1297 se parecen mucho al cód.46 Glosarium Abauus de San Millán.

Ninguno de estos seis glosarios registra vocablos romances. En este aspecto es más interesante la obra de un botánico sevillano que, alrededor del año 1100 , escribió en árabe un manual con las de 700 nombres de plantas, nombres muchas veces acompañados de su equivalente latino, y en numerosas ocasiones del nombre romance. Tiene interés para conocer mejor el habla mozárabe. Por ejemplo, $n^{\circ} 583$, latín «burmanty» (frumentum), romance «tridco» (trigo). Muchos de estos términos se identifican mal por estar escritos en árabe. Fue publicado por Asín Palacios en 1943. ${ }^{16}$

Finalmente, sí disponemos de tres glosarios latino-romances que fueron muy copiados, pero que nos han llegado en copias muy tardías, de los siglos XIV y XV: el Glosario de Toledo (principios del s. XIV), el Glosario de Palacio (fines del s.XIV) y el Glosario del Escorial (con letra del s. XV). Ofrecen unas 6.000 palabras latinas con su equivalente castellano, que a pesar de ser de una época tan tardía no dejan de prestar información sobre la evolución léxica de nuestro idioma. Fueron publicados por Américo Castro en 1936, y reeditados por Manuel Alvar bajo el título de Glosarios latino-españoles de la Edad Media. ${ }^{17}$

\section{LAS GLOSAS EMILIANENSES}

Entre los manuscritos españoles con glosas, ha venido ocupando un lugar preferente el que se conoce como $R A H$,cód.Aemilianensis 60 , escrito a fines del siglo IX, o principios del s.X. Está compuesto por el ensamblaje de dos códices preexistentes que ahora constituyen dos sectores de un mismo manuscrito. La primera de estas partes (fols.1-28) recoge textos de los Apothegmata Patrum (Sentencias de los Padres) que escribio San Martín de Dumio (s. VI), y la segunda (fols. 50-96) ofrece una colección de sermones de diversos santos, que el autor atribuye a San Agustín y que vienen a ser una selección de las llamadas

'5. García DE Diego, Glosarios latinos del Monasterio de Silos, Murcia, 1933. El cód. 1298, en CGL, V, 104-158.

${ }^{16} \mathrm{M}$. Asín PaLACIOS, Glosario de voces romances registradas por un botánico anónimo hispano-musulmán, Madrid, 1943.

17 Américo Castro, Glosarios latino-españoles de la Edad Media, prólogo de M. Alvar, Madrid, CSIC, 1991. 
Homilías Toledanas. Entre ambos sectores se intercalaron unos textos litúrgicos del oficio y misa de los Santos Cosme y Damián, y un officium de litanias.

Los dos códices primitivos salieron del mismo escriptorio y acaso de la misma mano. Se conjetura que fueron escritos en algún monasterio de la zona navarro-pirenaica, en el que se daba culto a San Cosme y San Damián.

Unidas ya las dos partes en un solo volumen, éste perteneció al presbítero Munio, que deja constancia de ello en el fol.28r con las palabras Munnioni presbiter librum (libro del presbítero Munio), y en el fol.48v deja entrever que él trabajó en este manuscrito, porque pide un recuerdo a los lectores, como solían hacer los copistas al final de su trabajo. Dice así: «Acuérdate del pequeño e indigno Munio».

Con el tiempo el códice vino a parar a la Biblioteca de San Millán, donde estuvo hasta la desamortización del año 1821 .

Pero la razón por la que se ha hecho célebre este códice es porque en él se escribieron las llamadas Glosas Emilianenses, una de las cuales, la número 89 , ha sido durante años considerada como el primer documento escrito en lengua castellana:

"Cono ajutorio de nuestro dueno dueno Christo, dueno Salbatore, qual dueno get ena honore, e qual duenno tienet ela mandatione cono Patre, cono Spiritu Sancto enos sieculos delos sieculos. Facanos Deus omnipotes tal serbitjo fere, ke denante ela sua face gaudioso segamus, Amen,» (fol.72)

La primera parte de este párrafo singular es la versión romance un poco parafraseada con añadidos del glosador de la invocación final de un sermón atribuido a San Agustín. Las últimas cláusulas (desde "Facanos...») es un arranque espontáneo y original del monje que pide a Dios en su lengua de cada día que él nos haga sentirnos gozosos ante su faz en el cielo.

Es la glosa más extensa, pero a ella le acompañan otras ciento cuarenta y cuatro que ofrecen interesantísimos datos para el estudio de los orígenes del castellano.

El códice, mientras no conste lo contrario, se da como glosado en el Monasterio de San Millán en el siglo XI, muy avanzado. Y buscando mayores precisiones J.M. Ruiz Asencio, basándose en los caracteres paleográficos de las glosas afirma que tuvieron que ser escritas a partir de los años 1070-1075. ${ }^{18}$

I8 J.M. RUIZ ASENCIO, «Hacia una nueva vision de las Glosas Emilianenses y Silenses», en Las Glosas Emilianenses y Silenses. Edición crifica y facsímil, Ayuntamiento de Burgos, 1993, p. 107. 
El autor de las glosas fue un monje. Se ha debatido largo y tendido sobre el sentido último de la incorporación de las glosas. Mucho más clara parece estar la utilidad de las numerosas anotaciones - cruces, letras, abreviaturas, etc.- que se distribuyen por todo el códice: son anotaciones de índole gramatical que le servirían de pauta para ir introduciendo a sus alumnos en los secretos de la lengua latina que les quería enseñar. ${ }^{19}$

\section{NuEVE LeCtURA DE ALgunas GLoSAS}

Un paso previo a cualquier interpretación de una glosa es la verificación de que nuestra lectura de la misma es correcta, es decir, que leemos exactamente lo que el glosador escribió. Este detalle no se ha cuidado debidamente, en parte porque se ha admitido reverencialmente lo que dijo el maestro $\mathrm{Me}$ néndez Pidal, y en parte porque hasta los años 1977 y 1992 no hemos dispuesto de una edición facsímil que permitiera comprobar, casi como en el original, las grafías del manuscrito. ${ }^{20}$

Hemos intentado una revisión de la lectura de algunas glosas, que creemos debe ser corregida, y como muestra ofrecemos tres de estas Glosas Emilianenses.

Glosa $n^{2} 10$ (fol.27v): Vix feci eum fornicari 'con dificultad hice que él (un monje) fornicara'.

Sobre la palabra vix 'con dificultad' el glosador hizo una anotación, que Menéndez Pidal entendió con muchas dudas como ueiza, ueza o uez. Así se ha repetido maquinalmente. Pero la verdadera lectura en 'fuerza', aunque la letra ' $\mathrm{f}$ ' está desvaída y en la parte superior borrada del todo. Vix, por tanto, debe

${ }^{19}$ Ya apuntado por Menéndez Pidal, ha sido estudiado en profundidad por varios autores: M.C.DíaZ Y DiAZ, Las primeras glosas hispánicas, Barcelona, Univ. Autónoma, 1978, pp. 27-29; J. FORTACín PIEDRAFITA, 1980, «Glosas morfosintácticas en el Códice Emilianense 60», en Revista de Investigación (Colegio Univ. de Soria), IV/1,pp.67-90; BIRTE STENGAARD, «The combination of glosses in the Códice Emilianenses 60 (Glosas Emilianenses)" en Latin and the Romance Languages in the Early Middle Ages, Roger WriGHT (ed.), London, Croom Helm, Romance Linguistics Series, 1990; M. CARRERA DE LA RED, «De nuevo sobre las glosas emilianenses", en Actas del II Congreso Internacional de Historia de la Lengua Española (Sevilla 1990). Pabellón de España, 1992, t. II, 579-595.

${ }^{20}$ Hay una edición facsímil de todo el Cód. Emilianense 60 : Glosas Emilianenses, Ministerio de Educación y Ciencia, 1977, con un estudio previo de I.B. OL.arTE. Otra edición facsímil s6lo de los folios del Cód. Emil. 60 que contienen glosas: Glosas Emilianenses, Gobiemo de la Rioja (1992), con un excelente trabajo preliminar de C. Garcla TURZA y M.A. Muro Añádase la edición crítica y fácsimil citada en la nota 18. 
entenderse como 'a la fuerza', 'con dificultad', que es lo que propiamente significa. ${ }^{21}$

Glosas $n^{2} 18$ y ne 19 (fol.65v): Et multiplicabitur beneficia 'y se multiplicarán los hechizos'.

A la palabra beneficia se le han puesto dos glosas. La una dice elos serbicios, o sea, los servicios, los favores. Pero esa interpretación no cuadra bien al sentido del texto, que habla de las señales que habrá al fin del mundo. Otro monje se dio cuenta del error porque debía entenderse ueneficia, y añadió otra glosa a la misma palabra. Pero ¿qué escribió este segundo monje? Menéndez Pidal y los demás tras de él, leen abientia. Palabra desconocida que nadie ha explicado. Nosotros leemos absentia, que en la Edad Media era el modo de escribir absintia (o absinthia) 'ajenjos', 'licores de ajenjo', 'bebidas amargas', que, según el Apocalipsis 8,11, será uno de los signos de la última hora del mundo. ${ }^{22}$

Glosas 131 y 132 (fol. 87r): Dicit etiam testimonium 'omnis caro fenum'. ('Dice también otro pasaje:' toda carne es heno').

Hay dos glosas: una detrás de Dicit etiam [Esajas] (Dice Isaias); la otra debajo de testimonium, en la forma siguiente:

\section{testimonium,}

ficatore, que debe leerse (testi)ficatore

El sentido está claro: 'Hay otro testimonio, siendo testificador Isaias'. Y en efecto se aducen las palabras de ese profeta $(40,6)$.

Menéndez Pidal dio la glosa 132 como ficatore y no trató de explicarla. Cuando nosotros la hemos dado en la forma (testi)ficatore, la repiten las demás, sin dar una cita, como si siempre la hubieran entendido así. ${ }^{23}$

${ }^{21}$ Esta lectura la defendimos ya en el Il Congreso de Historia de la Lengua (Sevilla, 1990). H.J. Wolf, Glosas Emilianenses, Hamburgo, 1991 (trad. en Sevilla, 1996). Sin embargo, ni RuIz ASENCIO, en la transcripción (p. 193), ni C. HeRNANDEZ, en su comentario (p. 258) la admiten, uno con invención de raspaduras en el texto, y el otro con la excusa de que «esta palabra no se acomoda a la traducción ni al contenido del textom( $i$ !).

${ }^{22}$ En 1990 defendimos también la lectura absentia, pero RuIz AsEncio sigue transcribiendo abientia (p.198), y lo mismo C. HERNÁNDEZ (p. 260), que nos acusa de forzar la lectura absentia para acomodar el texto, propone que abientia sea una glosa de praeda, y además que se traduzca por lo efimero $(i !)$.

2.3 También en esta glosa fuimos los primeros en leerla como (iesti)ficatore. Esta vez sí se admite la lectura, pero no se acuerdan de que Menéndez Pidal y S. Garcla Larragueta, Las Glosas Emilianenses, Logroño, 1984, leían ficatore a secas, sin que nadie los corrigiera hasta 1990. 
El ROMANCE EN LAS gLOSAS EMILIANENSES

Un vistazo rápido por las Glosas Emilianenses nos certifica que el glosador de San Millán se proponía como objetivo aclarar para sus alumnos el texto latino, valiéndose precisamente de la lengua vernácula de sus escolares. De las ciento cuarenta y cinco glosas, dejando a un lado la 31 y la 42 que están en vasco, y algunas otras de grafía borrosa, unas cien de ellas están en romance, y ventiocho en latín. Usó el romance sobre el latín en la proporción de cuatro a uno. Y esta proporción aumenta si se tiene en cuenta que algunas que hoy tomamos por latinas en el estado del castellano de entonces pudieran haber tenido uso normal entre la gente de la época. Así, pugna (4 y 96), verecundia (17), absentia (19), partitiones (16), promissiones (33) y seruire (37). Algunas, que hemos dado como latinas, son ciertamente romanceadas, v.g. quis cata qui huamne 'cada hombre' (128), y obi en vez de ubi 'donde' (121).

Otras que nos parecen indudablemente latinas, tenían entre el vulgo tal carta de naturaleza que resultaban de comprensión inmediata. Tales como, por ejemplo, quomodo (25, 50, 52 y 83), certe (77) y plus, majus (61 y 64).

También es curioso observar cómo el monje glosador se desenvolvía perfectamente en romance, aún teniendo que ponerlo por escrito, sin titubeos ni tachaduras, como se ve en la extensa glosa 89 «Cono ajutorio...». $Y$ no es esa glosa sola, sino que hay más de una docena de glosas que no se limitan a dar una palabra para explicar otra, sino que forman una frase entera:

- Elo terzero diabolo uenot (El tercer diablo vino) (9)

- Aluenge se feran (Se irán lejos) (15)

- Non conbienet a nobis (No nos conviene) (44)

- Nos si ficieremus (Si nosotros lo hiciéremos) (41)

- Nos non kaigamus (No caigamos nosotros) (43)

- Qui dat a los misquinos (El que da a los pobres) (48)

- Non se cuempetet elo uamne en siui (No se engañe el hombre a sí mismo)(68)

- Tardar-s-an por inplire (Se retrasarán en cumplirlo) (70)

- Non se bergudian tramare (No se avergiuenzan de entrar en pleitos) (75)

- Quemo eno spillu, noke non quemo eno uello (Como en un espejo, no como a través de un velo) (114)

- Nos enplir-nos-amus (Nosotros nos llenaremos) (124)

- Zerte dicet don Paulo Apostolo (Ciertamente dice el Apóstol San Pablo) (137) 


\section{LÉxICO}

A más de las fuentes latinas y del romance que entronca directamente con el latín, se advierten en las glosas términos ya aceptados procedentes de otras lenguas. Así:

- De las lenguas germánicas: gelemo (< helm) 'yelmo' (112); bruina (< brunja) 'coraza'(98); gerrare (62); jerrar (< werra) 'luchar', 'ofender' (141).

- Del árabe: misquinos (< miskin) 'pobres', 'desgraciados'. ata quando (< hatta) 'mientras'

- Del vasco: las dos glosas todavía no descifradas del todo: izio qui dugu (31) que glosa a meruimur 'merecemos' guec (c)ajutu ez dugu (42), glosa igual a nos non kaigamus 24 spillu (115) 'espejo', grafía que Menéndez Pidal cree influida por el vasco ispilu.

\section{MORFOLOGIA Y SINTAXIS}

Sin intención de hacer un análisis pormenorizado de todas las particularidades del escritor emilianense, sí vamos a señalar algunos detalles que llaman más la atención en estas glosas.

${ }^{24}$ M. PIDAL, Orígenes, 97.2: jzioqui dugu y guec ajutu ezdugu.- H.Viñes, «Primer testimonio escrito del vascuence navarro: el manuscrito emilianenes», $F L V, 49,1987$, pp. 41-52: çioqu dugu y guec ajutu eçdugu. - A. IRIGOYEN, «Las glosas emilianenses y la lengua vasca», en De Re Philologica Linguae Vasconicae, Bilbao, 1990, pp.15-29: «1. Izioqui dugu constituye con toda probablidiad un pretérito perfecto que debe traducir a (jnueniri) meruimur, aunque el participio incluido en la perifrasis verbal no es empleado en la actualidad en la lengua. La lectura de Menéndez Pidal es a todas luces correcta. 2. Guec ajutu ez dugu debe equivaler a la glosa non conuienet a nobis, refiriéndose ambas a non nobis sufficit, a pesar del orden de las glosas. El compararlo con nos non kaigamus no tiene ningün sentido.» Se podría hacer alguna precisión a las interpretaciones de tipo lingúístico de lrigoyen así como al fragmento latino a que se refiere la $2^{*}$ glosa vasca: guec caiutu ez dugu 'nosotros no hemos caído' no es un verbo sintético (la forma negativa de los sintéticos se dispone sintagmáticamente en otro orden: ez dugu nahi (nahi ez dugulako se da por tratarse de subordinación y nahi ez dugu disuena mucho a un vasco-hablante actual); guec como nominativo, es claramente sujeto, y dugu lo exige en ergativo, Irigoyen pretende hacerlo corresponder a 'nos', pero, aun cuando se acepte su existencia en algún estadio primitivo de la lengua, resultaría cuando menos extraño: $z u$ 'vos' zuec 'vosotros', quek 'nos' qu 'nosotros'. En cuanto a la variedad dialectal, parece probable que se trate de la propia de la actual Rioja (Vasconia perdida). Ni izioqui ni cajutu se conservan, y en ello radica la gran dificultad de estas dos Glosas Emilianenses vascas. Agradezco las observaciones a Jon Andoni, alumno de Filología Románica. 
Nombre: La reduplicación 'dueno dueno'. Cuando el texto latino ofrece la forma habitual (Domino nostro Jesu-Christo), el glosador la vierte al romance con esta otra:

Nuestro Dueno dueno Cristo, dueno Salbatore (89)

En donde se advierte que el pueblo cristiano daba a Cristo un tratamiento de particular reverencia (Dueno dueno = señor don ); además, el nombre Jesus se cambia por lo que significa en castellano 'Salvador' y se le antepone el título de reverencia: Dueno Salbatore 'Señor Salvador'.

Es de notar que los documentos notariales no dan el tratamiento de Dueno dueno, fuera de este caso, a ningún hombre por encumbrado que estuviere; en cambio, tanto en León como en Aragón, a ciertas mujeres sobresalientes se las distingue con títulos de Domna domna (Domna domna Sancia, Domna domna Oira...). Esto indica que se tributaba a las señoras un respeto similar a las personas más santas. ${ }^{25}$ No se trata, pues, como dice C.Hernández, de repetición del núcleo en un ejercicio gramatical, sino de una fórmula de tratamiento de aquella época.

\section{Artículo}

Las Glosas Emilianeneses lo dan en forma plena, en singular y en plural,en masculino y en femenino: elo terrero (68), ela sua face (89), elos serbicios (18).

Si precede una preposición terminada en - $n$, además de perderse la e- inicial del artículo, hay asimilación de consonantes: cono ajutorio (89), eno spillu (115).

\section{Verbo}

1) El perfecto muestra vacilación en la escritura de la primera persona desde la forma latina lebantaui (6), pasando por lebantai (3) hasta el perfecto romance trastorné (8).

También hay dudas en la $3^{\text {a }}$ persona: donauit (34), frente a fot (1), uenot (9), fezot (111) y sufriot (113).

2) El futuro imperfecto ya en el bajo latín había ido sustituyendo la forma sintética amabit por la perífrasis infinitivo más una forma de habere, v. g. 
amar-ha. El glosador emilianense tiene esta forma de futuro totalmente asimilada: uerteran (22), afflarát (29), kaderát (67), tu iras (103), ke farás (140).

También en formas pronominales: non se endrezarán (91), non se uiuificarat (135), aluenge se feran (15).

Otras veces el pronombre se intercala entre el infinitivo y el verbo auxiliar: nafregar-s'an (20), alongar-s'an (23), tornar-s'an (70), partir-s' an (109), nos lebar-támus (119), nos enplir-nos-amus (124).

3) El verbo ser. El latín est diptonga en jet (93-117), je (94), get (89). Y en la segunda persona es aparece igualmente como jes (138).

Del verbo sedere del que se ha formado ser, sólo tenemos la forma de subjuntivo segamus (89). Otra vez que aparece siedes (139) no traduce al verbo $\mathrm{ser}$, sino al verbo latino manes 'tú permaneces', glosa: siedes.

4) La voz pasiva. Se ha desechado la forma sintética latina y se usa la perífrasis de participio más verbo ser: data jet (93) y feito je (94).

\section{Adverbios}

Son típicas formas romances: lueco (2), anzes (47), de fueras (102), y los adverbios en -mente (-mientre): buenamientre (58). Sin embargo, por economía de espacio, el glosador a veces no escribe la segunda parte de estos adverbios, dejándola sobreentendida. Así: uoluntaria (88), reputatiba (145) y altra (116) (por altra mientre, o mejor acaso altra uece 'de nuevo', 'por segunda vez', como pide el sentido del texto). ${ }^{26}$

\section{Interjecciones}

Es curioso que, aparte de $o !=j o h !$, la única interjección latina que se le presenta al monje de San Millán -Eu me! - sólo se le ocurre glosarla por otra latina: Ue mici! (101).

\section{LAS GLOSAS SILENSES}

Íntimamente unido al códice de las Glosas Emilianenses se halla el de las Glosas Silenses. Es un manuscrito vendido en París en 1878 en una subasta de libros que habrían pertenecido al Monasterio de Silos, y que fue a parar a Lon-

${ }^{26} \mathrm{R}$. WRIGHT, op. cit., p. 303 , cree que aquí hay un posible malentendido del glosador, sin advertir que alteras es un adverbio latino que significa 'otra vez', y altra o altra (uece), lo mismo. 
dres, donde ahora está en la British Library, cod. addit. 30853. El profesor Ruiz Asencio lo data como posterior a los años 1080-1090, o acaso de los primeros años del siglo XII. También como «una hipótesis más que probable» sostiene la teoría de que «el Silense no es más que una copia de un códice hermano, perdido, del emilianenese, en el que también habría participado nuestro glosador» silense. ${ }^{27}$

Igual que el Emilianense, este códice está compuesto de dos partes principales: una (fols. 1-308 v) con sermones de los Santos Padres, especialmente las llamadas Homilías Toledanas, que eran leídas los días de fiesta en las iglesias de rito mozárabe. La otra (fols. 309-324 v) es copia de un penitencial ahora llamado Penitencial Silense, que describe un número considerable de pecados con la penitencia canónica que a cada caso correspondía, destinado a orientar a los sacerdotes en su tarea de ministros en la confesión sacramental.

De todo el códice lo que a nosotros nos interesa es este Penitencial, porque está iluminado con 368 glosas, la mayor parte de ellas en romance, que ya figuraban en el códice que sirvió de modelo, y que el nuevo copista colocó con esmero en los márgenes, señalando con idéntico signo la palabra glosada del texto y la glosa que le corresponde en el margen, utilizando las mismas claves que utilizaba el Emilianense. ${ }^{28}$

Hecha esta presentación, vamos a formular algunas observaciones para valorar mejor dichas Glosas Silenses.

NUEVA LECTURA O NUEVA INTERPRETACIÓN DE ALGUNAS GLOSAS ${ }^{29}$

Glosa 7 (fol. 310 v): sacrificium... uetustatum 'sacrificio envejecido', o sea, que se ha pasado de tiempo.

${ }^{27}$ En el estudio previo «Las Silenses son copia de un códice hermano del Emilianense», en Las Glosas Emilianenses y Silenses (pp. 116-118) ofrece hasta 8 pruebas que avalan su teoria. Pero puede haber algunas dudas sobre su argumentación. Por ejemplo: la primera prueba es «la aparición de uel abreviado a la carolina sólo en las glosas de ambos códices». En 1990 (p. 580 de la publicación) ofrecíamos la glosa misericordiam para la expresión $\neg$ medelam (uel medelam) en un añadido al cód. Emil. 62 de la RAH.

${ }^{28}$ Cf. J. M. RUIz ASENCIO, «Las formas alfabéticas y el sistema abreviativo [del Silense]», Las Glosas Emilianenses y Silenses, pp. 113-115.

${ }^{29}$ Esta labor es ahora posible gracias a la edición facsímil de las Glosas Silenses, ya varias veces citada, por cuanto con ella se puede trabajar casi como con el propio original del Penitencial Silense. Algunas lecturas nuevas y nuevas interpretaciones dimos a conocer en el artículo «Las Glosas Silenses; algunas precisiones», en JuAn PAREDEs (ed.), Medioevo y Literatura. Actas del V Congreso Internacional de la Asociación Hispánica de Literatura Medieval, Granada, 1995, pp. 523-539. 
A la palabra uetustatum se le añaden dos glosas: betereiscitu, palabra latina romanceada igual a 'envejecido', y osmatu, palabra que Menéndez Pidal no explica, ni tampoco C. Hernández (op. cit., p. 272). Se trata de una latinización del adjetivo griego őoū que da mal olor'.

Glosa 23 (fol. 311 r): Femine religiose 'las mujeres religiosas'. A la palabra religiose le añade una aclaración que dice: et sanctas, mondas '(religiosas) y santas, limpias'.

Ruiz Asencio (op. cit., p. 227) lee el término mondas como uiudas, cuando lo que hay en el códice es mondas corregido como mundas, como en el fol. $324 \mathrm{r}$ escribió obolum, corregido en obvlum).

Glosa 66 (fol. 313 v): Perficere sepultura eius 'señalarle sepultura'. El infinitivo perficere es glosado por ke li fican 'que le asignen [sepultura]' entre los demás fieles a aquel que ha sido inducido por el demonio a darse muerte. Lo erróneo en este caso es el comentario de C. Hernández (op. cit., p. 275) que dice: «Ficere aparece como variante de facere». Fican es el subjuntivo latino figant 'fijen, marquen, señalen'.

Glosa 114 (fol. 315 r): La glosa puesta al margen izquierdo dice así: auctores, cantationes, tores, que se ha interpretado (Ruiz Asencio, p. 235) como auctores, cantationes, (canta)tores. Creemos que la terminación -tores no corresponde a canta-tores, sino a somnia-tores 'soñadores', porque la línea termina con la palabra somnia y justamente la línea 12 empieza con -tores, por lo cual, leyendo una tras otra, se lee: somnia-tores.

Otra razón que abona esta lectura es que las demás palabras de esas dos líneas llevan su glosa, y somnia no estaría glosado. El sentido pide esta interpretación, pues el texto quiere reprender a los cristianos que hacen a los encantadores, a los soñadores, y a los que pronostican la suerte futura (sorteros).

Glosa 138 (fol. 316 r): Se inbicem coinquinantes, que se glosa así: uno con altro sese inquinaren 'los jóvenes que se mancharen uno con otro'. El penitencial está nombrando pecados de fornicación, y aquí habla de la homosexualidad entre los jovenes.

No es admisible la versión de C. Hernández (p. 280) cuando traduce: «Peleasen uno con otro mutuamente».

Glosas 187 y 188 (fol. 317 v, 318 r): Digami..., trigami. Las glosas de estos dos términos son: Vir secunde uxoris... tertie uxoris, como se ve, son latinas que quieren decir: «el hombre que toma una segunda esposa y el que toma una tercera», pero no se refiere a los que tengan dos o tres mujeres a la vez (bígamos o trígamos), sino al que contrae segundas o terceras nupcias, que en aquellos tiempos no era bien visto. La penitencia que se les señala es de un año 
y de dos respectivamente. La prueba de ello es que en el fol. $316 \mathrm{v}$ ha hablado del laico que sin matrimonio tuviere tres mujeres debe dejarlas y no se case más, y haga larga penitencia. Por tanto tampoco aquí acierta César Hernández (p. 282) cuando apostilla lo siguiente: «La glosa latina no parece necesaria para un lector mínimamente culto».

Glosa 308 (fol. 321 v): Abstinere a... sanguine et suffocato 'abstenernos de... comer la sangre y la carne de animal estrangulado, sin haber sangrado'. Es el precepto que ordenan guardar los Apóstoles (Actos 15.29).

Suffocato se glosa libremente por mortizino 'animal muerto sin sangrar (se entiende)'. La versión de C. Hemández (p. 287) es como sigue: «asado (< suffoco 'poner al fuego')». Pero suffocato significa 'estrangulado, ahogado', como lo reconoce el mismo autor en la glosa 324: stranguilantur [sofocatos foren]. ${ }^{30}$

\section{PROPORCIÓN ROMANCE/LATÍN}

El glosador silense quiso aclarar un texto más largo que el emilianense y emplé 368 glosas, frente a las 145 de aquél. A pesar de ello, la proporción romance/latín que emplea el silense es idéntica a la usada por el emilianense; dicha proporción es de 4 a 1, aproximadamente, en favor del romance.

Hay en torno a 80 glosas latinas, pero, dado el estado de evolución en que se hallaba el romance en el siglo XI, podemos pensar que muchos términos latinos eran de uso normal entre los que hablaban romance. Así punga (= pugna) (48), jectatis (53), memoria (60), abortare (88), culpauiles (106), annos (150), prima junctatione (= matrimonio) (163), lures faces (= sus caras) (261), scriptura (313), uenia (353) y plebe, populo (362).

Algunos de estos términos que, según su grafía, parecen latinos, por la preposición que los precede se ve que están usados como romances: a salutare (19), con benedictione (15), de la lebatione 921), de artificio (82), en frangitate (= por fragilidad) (215), ad uota (= a bodas) y algunas más.

Finalmente hay glosas con verdadero sabor latino, pero que son empleadas porque al glosador le parecían más propias y más aclaratorias: christianus por catholicus (25), corpora por cadauera (62), debiles por inualidis) (26), infecunda por sterilis (143), reliquias por martyria (tumbas de los mártires) (40), etc.

30 Suffocare, en latín decadente, tiene dos acepciones, según el término de donde proceda: suffocare (derivado de fauces) significa 'ahogar a uno, apretándole la garganta', suffocare (derivado de focus 'hogar', 'fuego') significa 'sofocar', 'apagar el fuego'. Aqui tiene el primer sentido, o sea, 'ahogar', estrangular'. 
Ciertos adverbios y conjunciones latinos los sustituye por otros más corrientes: semper, deinde y autem, como mejor conocidos.

\section{GLOSAS DOBLES Y TRIPLES}

Frente a la naturaleza de las glosas del Emilianense que constan de un sólo término o de una expresión, casi todas, las del Silense, en cambio, frecuentemente ofrece glosas dobles y, en ocasiones, triples, en las que combina bien dos términos latinos, bien uno latino y otro romance, o dos términos romances. Ejemplos:

Latin-latin: dat et donat (95); in damnatione, in carcere (208); cogitet, speret (212); pasceret, gobernaret (235); manifestaret uel predicaret (270).

Latín-romance: et sanctas, mondas (23); ministrent, sierben (49); occisiones, matatas (52); occidunt, mata( $n)(81)$; in tantum, por en ende (85); rogarent, si pitent (196); retro, ad abiesas (257); nisi, gestra (285); discordantium, odiosos (302); finiuntur, stranglatos fuerent (319), y otras.

Romance-romance: debiles, aflitos (26); por fere, ke faciat (45), eno periculo contendieret, se acertaret (47); de lo adversario, gentile (96); laiscare(t), saket (123), y otras: $169,193,219,347$.

Hay términos latinos glosados por tres términos romances:

barbaris: a los gentiles, paganos, mozlemos (51); emisor tempestatum: feritore, zetator, grandionero (73); consentit: sientet, scuita, placet (125); ad proximas: a los justanos, bicinos, parentes (296).

Esta abundancia de miembros en las glosas romances parece demostrar que el monje de Silos dominaba extraordinariamente la lengua materna y quería ofrecer a sus destinatarios un repertorio léxico que ellos pudieran luego escoger a su gusto.

\section{FRASES ROMANCES}

El monje de Silos no tuvo la ocurrencia de poner por escrito un párrafo tan elocuente como el «Cono ajutorio...» del emilianense. Pero seguramente era tan capaz, o más, para haberlo hecho. Así se desprende del rico vocabulario que 
utiliza, y también de ciertas frases que se pueden espigar en sus anotaciones, aunque sea uniendo dos o tres glosas contiguas:

- Poca labatu siegat aqua (10-12).

- Apretaret... ke se perjuret super so cosa (33-34) ('El que obligare a otro a jurar en falso en favor suyo').

- In carcere puestos siegan ata ke mueran (208-210).

- Asi mandat ka nicuno non deuemus (315) [comer la sangre].

- Mondo sedere, mientre preinnaret (205) (Mantenerse limpia la mujer mientras estuviere embarazada).

Y bastantes frases más que dan idea del avanzado estado de evolución a que estaba llegando el romance centro-peninsular a fines del siglo XI, y nos permiten pensar que de no haber tenido el glosador tanto respeto al latín, hubiera sido capaz de producir algunas obras notables antes del Mio Cid y de Berceo.

\section{LA GRAMÁTICA DEL SILENSE}

No difiere en lo fundamental del Emilianense, aunque cada uno tiene sus peculiaridades, dado el distinto carácter de los textos que glosan.

1) Las formas del perfecto que en el Emilianense abundan por ser texto narrativo, aquí escasean: tolliot (41), duplicaot (86 bis), cadiot (274); betait 'vedo' (318).

2) El tinte jurídico que tiene el Penitencial Silense hace que abunde en él el futuro imperfecto de subjuntivo con su sentido hipotético: 'el que hiciere...'Se dan más de 40 casos de empleo de esta forma verbal. los más abundantes son: auieret $(132,283,367$ y 368$)$; ficieret $(37,133,152$, y 243$)$ y otros.

3) El verbo ser en su infinitivo latino esse se traduce dos veces por sedere (72 y 238), y otras dos veces por una forma personal: ke jet (272) y ke son (273).

En los demás tiempos, la glosa romance se deriva de la latina est en la forma jet $(279,278,317)$, y otras de sedeat en la forma siegat, siegant $(9,11,29$ etc. y 179, 209, 227, etc.).

4) El participio pasivo se emplea para formar la voz pasiva con las terminaciones -to y -tu en singular y -tos en plural. Hemos advertido que por dos veces (92 y 192) se emplea el participio pasivo para formar con el verbo ser los tiempos compuestos de la voz activa con los verbos de movimiento: cadutu fueret 'hubiere caído'. Fenómeno que perdura en francés y se ha perdido en castellano. 
5) El participio de presente latino se ha perdido, y el glosador lo traduce unas veces por gerundio (non sapiendo, 17 y 32), y otras por una forma personal (si non sapet, 27).

6) Hay en el Silense algunas formas raras de adverbios: numquam, glosado (non] alquantre (de: non aliquantele 'ni un poco') (126), aunque Menéndez Pidal (Orígenes, 77,3) dice que deriva de [non] aliquando; forsitan, glosado alquieras (200 y GlEmil. 69) de aliudquaeras, pero es difícil de entender esta glosa.

Entre los adverbios en -mientre hay uno especialmente llamativo y no fácil de esplicar: uiolenter, glosado fuerte mientreza (131). No hay otros ejemplos que demuestren que mientre = mientreza.

7) Entre las conjunciones la más frecuente es $k e$ (que) y sus compuestos: ata que (210, 240 y 328), macare ke 'aunque' (281) y pos que (44), ante que (206). Una vez aparece la forma $k a=q u e(315)$.

\section{LÉXICO}

Destacamos sólo algunas voces que nos pueden dar una mejor idea del estado de evolución del español en estas glosas.

\section{Nombres}

Destello (14) (de stilla 'gota') «Por el cobdo ayuso la sangre destellando» (Mio Cid 1724)

Fornicio (82) ('fornicación') «Que te cortes los miembros que facen el fornicio» (Berceo, Mil. 192b).

Antamios (90) ('círculo del año') (De ambitare 'andar', 'caminos, sendas').

Vergoina (171) ('verguienza') (De verecundia > vergondia > vergonia $>$ vergoina, [vergora], una evolución que se frenó ante el avance de: verecundia $>$ vergontia $>$ vergüenza ).

Entraina (239) ('lucha') (De pugna interanea 'lucha intestina, lucha interna').

Azetore (325) ('azor') (De acceptorem > aztore > azor ).

Verbos

Afflaret (5) ('hallar') (De afflare 'olfatear (el perro de caza)')

Kematu siegat (9) (De cremare 'quemar')

Matare (58) (De mactare 'sacrificar')

Scuitare (120) ('escuchar') (De auscultare)

Applekare (127) ('(a)llegar') 
Brazaret (137) ('abrazar')

Aketare (190) ('aquietar', 'estarse quieto') (De quietem 'descanso, quietud') Kisieret (200) ('quisiere') (De quaerere 'buscar')

Voces que se han perdido

Nafregatu (6) 'destruido'. En Aragón queda nafrar 'herirse por rozamiento' Fican (gl.22) 'señalen, fijen'. En portugués ficar 'quedar'.

Campas (139) 'piernas'. En catalán cames, francés jambes, it. gambe.

*Quencoba (167); concuba, en San Isidoro. En castellano concubina.

Ibizone (199) 'macho cabrío'. Aumentativo de ibicem 'cabra montés'.

Voces de origen no latino

- Del árabe: mozlemos (51), ata ke (240), malatas (170) ${ }^{31}$

- De las lenguas germánicas: gasaillato (230) 'compañía, trato con los compañeros' (del germánico gassalian 'compañero); hasallos (247) (del germánico guas 'servidor')

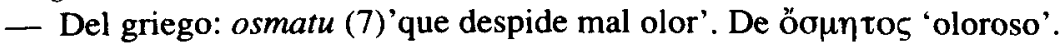

Voces desconocidas

Cemajacione (197) 'prostituta, o prostitución', por el contexto, pero de etimología no conocida.

Magatias (236) es glosa del latín malas 'mejillas'. Étimo desconocido.

NOTA FINAL

Los glosadores de estos dos códices, como aquellos otros que intervienen en la elaboración, ilustración y distintas tareas necesarias para la transmisión de textos en el medioevo español y europeo, tal vez no sabían mucho latín, pero su espíritu innovador abría caminos en los niveles gráficos y en las correspondencias de términos léxicos así como en las tareas de reanálisis de las estructuras gramaticales por las que luego iban a transitar los hablantes de los romances peninsulares de esta zona centro.

"Según Gómez Moreno, mallatus 'criado' en árabe. 